on a correct solution; this form is much more rapid, can deal with a greater number of variables but gives only one of the possible answers.

Also among the 'guest' exhibits was an amateur radio station in full operation, complete with homemade radio transmitters and receivers and a television receiver.

In the research section, Imperial Chemical Industries (Dyestuffs Division), Ltd., displayed a light-flux integrator. A photo-cell charges a condenser which triggers a flip-flop circuit at a given charge-level. This operates a counter, discharges the condenser and resets the circuit for the next count. A range of instruments involving transformer-type electromagnetic displacement gauges were on show. One such device measured the rate of wetting of a textile sample in water by recording the movements of a torsion balance, to which the sample was attached, as the water was absorbed.

The Electrical Engineering Department of the Manchester College of Technology displayed apparatus illustrating both research carried out in the College, and devices used in teaching. In the former category was an apparatus for indicating the rate of change of mains-frequency directly on a single dial, and designed for use in power stations. A useful device for teaching purposes was a harmonic synthesizer in which one could see, directly on a cathoderay tube screen, the effect of adding together various proportions of different harmonics.

In the trade section there was a bewildering variety of equipments, all beautifully finished and a large proportion of them actually in operation.

Ferranti, Ltd. (Hollinwood), demonstrated their mercury-argon crater lamps, which give a light output directly proportional to the current passing through the lamp. These have wide application in sound-film recording and picture transmission, as the light can be modulated at frequencies up to $12,000 \mathrm{c} . / \mathrm{s}$. Among other interesting items was a new flat-faced television picture-tube with a 14-in. diagonal rectangular screen.

Fielden (Electronics), Ltd., demonstrated a yarnirregularity meter. The instrument effectively determines the mass of a centimetre length of yarn, instantaneously present in the gap of a special condenser head, in terms of its dielectric properties. The instrument then notes the irregularities, integrates them over a predetermined period and presents the result, on a single dial, as the average irregularity expressed as a percentage of the average mass of the sample. The reading is quite steady and independent of the speed at which the sample is passing through the instrument.

One of the most interesting exhibits on the stand of Marconi Instruments, Ltd., was an audiometer assembly, specially designed for measuring the hearing acuity of young children. The instrument incorporates a standard pure-tone audiometer. The portion of the instrument visible to the child is brightly decorated in nursery style and consists of a loud-speaker and a 'peep-show' arrangement. This is so devised that a brightly coloured picture becomes visible when the child presses a button, provided that a test signal is being applied to the loud-speaker.

The Metropolitan-Vickers Electrical Co., Ltd., displayed their high-speed, recurrent-wave-form monitor which gives, on a cathode-ray tube screen, a trace of a recurrent wave-form with frequency components up to $300 \mathrm{Mc} / \mathrm{s}$. In any one cycle, the instantaneous amplitude at some one point of the wave-form is measured. On successive recurrences, the instantaneous value at other points is recorded and after about 200 cycles a complete picture of the wave is available.

Mullard, Ltd., had on view a number of important additions to their range of valves, including a new disk-seal ultra-high-frequency triode, with a new type of cathode which permits closer spacing of electrodes -with consequent higher maximum frequency of operation - than has hitherto been obtainable, a səries of sub-miniature valves and the first members of their range of image-converter tubes.

The Exhibition Committee deserves special congratulations on the organization, which, at any rate to an outside observer, appeared to be particularly free from technical hitches. $\quad$ C. A. TAYLor

\section{RESEARCH AND DEVELOPMENT IN THE SIMON ENGINEERING GROUP}

\author{
By DR. W. RHEINALLT THOMAS \\ Director of Research
}

$T$

HE year 1908 saw the establishment of the first Simon Laboratory for examining and testing the materials used and produced in the coke ovens and coal-washing plant then being built by the firm. In 1912 tests associated with the manufacture of sulphuric acid were also undertaken. In the period between the two World Wars, the Laboratory was enlarged on three occasions to cater for advances in the design of existing plant and the introduction of new activities, which now include the production of power stations, turbine gears and a wide variety of chemical plant and mechanical and pneumatic handling machinery. Each department had also set up its own small teams of research workers and technical development engineers.

Tremendous expansion followed the Second World War, as demonstrated by the fact that orders to the value of $£ 75$ million have been taken at home and abroad, and it became clear that existing arrangements for testing, research and development were inadequate. Plans were drawn up to meet the situation, and building began in mid-1949.

On July 3 last, Sir Henry Tizard opened the new buildings, consisting of a central research block, a testing wing housing what was known as the Laboratory and now forming part of the Research Department, and the first of two development wings. These new buildings are almost entirely devoted to the research and development interests of SimonCarves, Ltd. The Henry Simon companies forming the other half of the Simon Engineering Group, and with very different fields of activity, have entirely independent facilities for research and development, although there is the closest co-operation, particularly where problems of mutual interest are concerned.

The central research building, $159 \mathrm{ft}$. long, $45 \mathrm{ft}$. wide and $45 \mathrm{ft}$. high, contains four research laboratories, microscope, balance and dark rooms, as well as sections for testing metals and refractory and building materials. The library, information room and offices occupy the central portion of the first floor.

The testing wing on two floors is $105 \mathrm{ft}$. Iong, $55 \mathrm{ft}$. wide and $25 \mathrm{ft}$. high, and is specially designed to cater, on a much enlarged scale, for the activities of 
the old laboratory. The chemical work is carried out on the first floor, where four laboratories and ancillary rooms are provided. The ground floor contains six laboratories for the mechanical and physical testing of coal and coke, as well as a large workshop capable of dealing with all research and development requirements.

The development wing is a single-story building $165 \mathrm{ft}$. long, $55 \mathrm{ft}$. wide and $45 \mathrm{ft}$. high, and is devoted to experimental pilot plant on coal washing, coke ovens and pneumatic handling machinery. Until such time as the second wing is erected, space has been allocated in the existing wing to the chemical and power-plant development sections.

The main lines of activity fall into four broad classes: chemical analysis and materials testing; research ; information; technical development. The division is arbitrary but convenient; overlapping is inevitable and only brief descriptions are given here of a few features of the work.

Before any plant is designed, exhaustive laboratory investigations are carried out on the materials to be used and produced, so as to provide the designer with data that will enable him to predict accurately the suitability of the raw materials and guarantee the performance of the plant.

For coal-washing plant design, information is given on the separation of coal and shale and of the fine coal and tailings as well as for the treatment of water for re-circulation. The assessment of coal for use in coke ovens involves proximate and ultimate analyses, determinations of the swelling properties, the yields of coke and by-products and analysis of the gases evolved. For boilers and power plant using either stoker or pulverized fuel, the calorific and ash fusion values are also determined.

The refractory materials employed in coke ovens are subjected to stringent tests for completeness of firing and strength under load at high temperatures and for resistance to abrasion and to sudden changes of temperature. Building materials undergo rigorous tests and analyses prior to use. A number of mechanical, physical and chemical tests are also carried out on the metals used in plant construction.

The general chemical analyses cover a wide range of organic and inorganic compounds as well as complex ores. Forty-four by-products of coal are analysed as a matter of routine. In connexion with the manufacture of sulphuric acid, catalysts, pyrites and the finished acid are examined, and such problems as treatment of waste acids and gases and phenol recovery from effluents form part of the programme.

To meet the needs for testing facilities on sites, a self-contained mobile laboratory has been fitted up and, by means of interchangeable cabinets, equipment can be quickly changed to permit tests on every type of plant built.

Research on a centralized as opposed to a departmental basis is of recent origin. Some of the problems embrace the activities of the organization as a whole; others are mainly of sectional interest. Reference is made to one of each type.

One field of common practical interest concerns small particles which are involved in the collection, extraction and disposal of industrial mists and dusts; the combustion of pulverized fuel and sulphurbearing ores; sedimentation and studies in magnetization for dense medium washing.

The restriction of imports of raw sulphur for sulphuric acid manufacture has made it urgently necessary to devise means of purification and recovery of sulphur from alternative sources. The fields of investigation cover the filtration of molten sulphur, the, flash roasting of iron pyrites, recovery from waste gases and spent liquors, and removal of hydrogen sulphide from town's gas.

The information section comprises a library and an information staff dealing mainly at present with the scientific and technical needs of the organization. By virtue of its activities it will possess an over-all generalized picture of the whole field of interest rather than a specialized knowledge of part of it.

The three main contracting departments in the organization are the coke-oven and coal-washing department and the power and chemical plant departments, and each has its own technical development sections. Work, hitherto, has been largely carried out on full-scale industrial plant. With the advent of the new wing, however, experiments on the pilot-plant stage will be carried out at first for rationalizing the design of existing plant and later in applying fundamental data to the design of new plant.

The new wing houses a complete dense medium coal-washing plant to one-third full scale, in which up to 25 tons of coal per hour can be treated, and effective separation of coal and shale differing only slightly in density is achieved. From trials on this plant and from the results of the associated laboratory tests, it is possible to erect full-scale plant of guaranteed performance. It will also be used for improving performance and for trying out new ideas. A smallscale self-contained coke oven has also been installed, and the results obtained can be translated to full-scale practice. An integrating radiometer establishes the combustion characteristics of domestic coke.

A pilot distillation plant in process of erection represents development of a new process where an entirely new design of fractionating column promises high efficiency in small volume.

The development sections of the power plant and chemical plant departments await the erection of the second development wing. In the meantime their work continues to be done largely on actual plant; but they have been allocated space temporarily in the existing wing. A test assembly of axial cyclones for gas cleaning has been erected, and at a later stage pilot plant for work on electrostatic precipitation will be installed. The chemical plant section is also co-operating with the British Iron and Steel Research Association in developing a method of recovering sulphuric acid from spent pickle liquor at steelworks. Among the main problems which the power-plant development section proposes to examine in detail are the behaviour and characteristics of pulverized fuel, the treatment of carry-over in steam and the expanding of tubes into drums and headers.

Recruitment of staff for the research department is proceeding and the ultimate establishment proposed will total 55, consisting of the director of research, twelve graduates of varying degrees of seniority, twenty-seven laboratory assistants, ten junior assistants and an administrative staff of five.

Each technical development section has its own staff headed by a senior scientific man. The coke oven and washer department has a team of six graduates, two senior and two junior assistants as well as a team for plant supervision and maintenance. The power-plant section has four graduates and one senior assistant, and the chemical plant section two graduates. Increases will be made when the second development wing is erected. 